\title{
A FENOMENOLOGIA COMO ABORDAGEM METODOLÓGICA: COMPARTILHANDO A EXPERIÊNCIA DE MULHERES QUE BUSCAM A PREVENÇÃO DO CÂNCER CÉRVICO- UTERINO*
}

Regina Lúcia Mendonça Lopes Ivis Emília deOliveira Souza**

LOPES, R.L.M.; SOUZA, I.E.O. A fenomenologia como abordagem metodológica: compartilhando a experiência de mulheres que buscam a prevenção do câncer cérvico-uterino. Rev.latino-am.enfermagem, Ribeirão Preto, v. 5, n. 3, p. 5-11, julho 1997.

O artigo objetiva trazer a experiência da apropriação pela enfermagem da fenomenologia como abordagem metodológica e do pensamento filosófico de Martin Heidegger, expresso em Ser e Tempo, para a compreensão da mulher que busca prevenção do câncer cérvico-uterino, possibilitando a reflexão sobre a assistência de saúde à mulher.

UNITERMOS: enfermagem, saúde da mulher, fenomenologia, metodologia de investigação fenomenológica

\section{O ENCONTRO COM A FENOMENOLOGIA}

O desenvolvimento da tese de doutorado sob essa abordagem justificou-se na sua proposta de buscar a compreensão do humano em seu cotidiano vivencial, por meio da descrição do fenômeno*** que a experiência dos fatos nos oferece para chegar a sua essência. $\left(\right.$ LOPES $\left.^{6}\right)$.

Porém, considerar esse caminho como possibilidade significou reconhecer que o referencial técnico-científico das ciências naturais não era adequado para esclarecer questões referentes à existência humana detectadas no meu dia-a-dia assistencial.

A partir da minha prática profissional como enfermeira supervisora de um ambulatório de ginecologia durante o período de 1987 a 1992, observei a situação da baixa demanda ao exame preventivo ginecológico, a despeito de esforços despendidos pela equipe de saúde na realização de ações educativas. Também observei que as mulheres ao vivenciarem o exame, o faziam de maneira assustada, temerosa, sofrida e envergonhada e detectei, assim, não só a relação pouco consciente com o próprio corpo, existente no cotidiano feminino, mas também o desconforto que o assunto - exame ginecológico - trazia. Percebi que tal fato influenciava em suas decisões futuras de aderir ou não a programas de prevenção.

Por outro lado, a vivência pessoal fazia-me refletir sobre o ser humano que sou e que, de modo único e singular, também vivenciava, como mulher, o cotidiano da prevenção. Não encontrava, no discurso explicativo, o caminho para responder às minhas inquietações.

Nesse sentido, a partir desse olhar atentivo, pude refletir sobre a inadequação do saber científico clássico, para conduzir-me à compreensão do grande vazio que se estabelece entre os programas de prevenção do câncer cérvico-uterino e a adesão das mulheres a eles. Vislumbrei a Fenomenologia como possibilidade de desenvolver a temática câncer cérvico-uterino nessa dimensão compreensiva.

No entanto, optar por essa abordagem também significou ousar adentrar no universo filosófico e, de um modo bastante apreensivo, reconhecer essa lacuna existente em nossa formação acadêmica como enfermeiros.

Meus primeiros momentos de impacto com esse saber filosófico ocorreram quando cursei a Especialização em Educação, oferecida na modalidade de Nivelamento ao Curso de Mestrado em Educação na Universidade do Estado do Rio de Janeiro (UERJ). Ao mesmo tempo, de modo surpreso e tranqüilizador, deparei-me com uma

\footnotetext{
* Recorte da Tese de Doutorado em Enfermagem $\mathbf{O}$ avesso da prevenção do câncer cérvico-uterino: o existir feminino sob a ótica da enfermagem - defendida na EEAN/UFRJ em março de 1996

** Professora Orientadora da Tese

*** Fenômeno - aquilo que se mostra em si mesmo e que é objeto de interesse da Fenomenologia

Fato - objeto de interesse da ciência, caracterizado pelo que é passível de observação, verificação, mensuração, repetição e controle
} 
significativa produção científica nacional e internacional desenvolvida com o suporte da Fenomenologia, por enfermeiros docentes e assistenciais que dirigem suas preocupações para a compreensão de muitas situações de saúde e doença experienciadas pela clientela em sua totalidade existencial. Tal produção expressa a elaboração cuidadosa de teses, dissertações e artigos e evidencia a eleição de pensamentos filosóficos desenvolvidos por Martin Heidegger, Maurice Merleau-Ponty e Alfred Schutz.

Com o intuito de aproximar-me dos pressupostos filosóficos da Fenomenologia, bem como de definir-me quanto ao filósofo de suporte para o desenvolvimento da investigação a ser realizada no Curso de Doutorado em Enfermagem, busquei participar de cursos e outros eventos. Assim, cursei a disciplina Filosofia Contemporânea do Curso de Mestrado em Filosofia (UERJ) e participei de Cursos de Extensão em Fenomenologia (UERJ). Nessas oportunidades, constatei o interesse de profissionais de enfermagem na busca dessa abordagem para a compreensão de questões significativas à existência humana, como o medo, a angústia, a tristeza... e a apropriação desses conhecimentos para a melhoria da assistência de enfermagem.

Além de proceder a leituras de obras referenciadas nos citados cursos, tarefa que, pela terminologia específica, muitas das vezes realizei com dificuldade e de participar de discussões coordenadas por docentes do Curso de Doutorado, cursei as disciplinas Tópicos de Filosofia Contemporânea do Curso de Especialização em Enfermagem da Mulher e Obstetrícia Social e o Curso de Enfermagem e Fenomenologia, ambos oferecidos pela Faculdade de Enfermagem da UERJ e Introdução à Pesquisa Fenomenológica ofertada no Curso de Doutorado Interunidades na Escola de Enfermagem de Ribeirão Preto da USP. A ministração de conteúdos desenvolvida por docentes da área de Filosofia que discutem a utilização da abordagem pelas ciências da saúde e o encontro com meus pares possibilitou uma reflexão aprofundada sobre temas de interesse profissional na busca de uma assistência mais humanizada.

Essas várias estratégias conduziram-me a repensar o meu assistir à clientela nessa situação existencial de vivenciar o exame preventivo. Dessa interação profissional cotidiana emergiu o meu sendono-mundo-com-a-cliente, esta que nos vem ao nosso encontro no mundo-vida de um ambulatório e que, como ser "ex-sistente", vivencia o exame de maneira própria, em seu sendo-no-mundo, segundo seu sentido, sua direção, seu modo de ser.

Foi de maneira ousada e desafiadora que, como docente e enfermeira, optei pelo caminho da Fenomenologia, para a compreensão do outro, a quem me foi confiado o cuidado, tendo o pensamento filosófico de Martin Heidegger, expresso em Ser e Tempo, como suporte para o desenvolvimento do estudo. Respaldada na obra em que o autor parte para a descrição da "exsistência" desenvolvendo os modos de ser do acontecer humano em sua cotidianidade, foi possível apreender o sentido do ser-mulher, ou seja, os modos de ser da mulher na situação cotidiana de cuidar de sua saúde.

\section{TRAJETÓRIA DO ESTUDO}

\section{Abordagem Metodológica}

DONZELLI ${ }^{4}$, ao discorrer sobre o método fenomenológico, afirma que este busca a compreensão do ser humano no seu "ex-sistir". Ser que possui uma vivência de consciência única e singular.

Como opção metodológica, segundo BOEMER ${ }^{1}$, sua escolha depende do objeto de estudo e, principalmente, do sujeito questionador, pois, antes de mais nada, é uma postura diante do mundo. É uma atitude de abertura do ser humano para a compreensão da vivência a partir do outro, parceiro do pesquisador em seu processo de descoberta (BOEMER ${ }^{2}$ ). É essa possibilidade de compreensão que impulsiona o investigador.

É um caminho significativo para o pesquisador que, a partir de suas inquietações, busca o fenômeno através de quem vivencia uma determinada situação. Esse caminhar fenomenológico, segundo REZENDE ${ }^{8}$, é a opção por um estilo de trabalhar, de pensar, de agir, de discursar e de se posicionar diante dos homens, do mundo, da história e da sociedade.

Estar diante do obscuro possibilita ao pesquisador olhar atentivamente, surgindo, então, uma questão inquietadora. A região de inquérito, de investigação, encontra-se, pois, no mundo onde o fenômeno se dá, situase no nosso cotidiano, enquanto ser-aí-com-o-outro.

Minhas inquietações levaram-me à seguinte questão: - Qual é o sentido que funda o comportamento do ser-mulher ao realizar o exame ginecológico, para a prevenção do câncer cérvico-uterino? É o objeto de estudo situado no mundo onde se dá o fenômeno, descrito por quem o está percebendo, sentindo, vivenciando, enquanto existente.

Nessa abordagem metodológica, o conhecimento que tenho sobre a temática constitui o meu pré-reflexivo. $\mathrm{Na}$ maneira diferenciada de olhar, surge o que HEIDEGGER $^{5}$ denominou de estabelecimento da posição prévia. É a atitude do observador que põe em suspensão qualquer teoria, crença, concepção, conhecimento prévio sobre o estudado para ir em busca da pré-compreensão. 
É não negar a facticidade, mas, sim, colocar entre parênteses os preconceitos e os pressupostos oriundos de um pré-reflexivo vivenciado e experienciado.

Assim, na condução do método fenomenológico, no entender heideggeriano, preconiza-se $o$ desenvolvimento de momentos denominados como estabelecimento da posição prévia, que implica na suspensão de todo o conhecimento factual e no estabelecimento da visão e da concepção prévia. O acontecer desses momentos ou pressupostos permite a mostração do fenômeno como sentido,compreendido como modos de ser.

Vendo e observando espaços e tempos próprios e captando os mundos assim em constituição, através da fala originária, ocorre, então, o desvelamento do fenômeno. A captação dos mundos próprios é, pois, segundo CARVALHO ${ }^{3}$, o ver e o observar em uma entrevista de natureza fenomenológica. É isto que possibilita captar o sentido. A autora enfatiza que compreender não é explicar, pois não diz respeito a fatos e causas, mas, sim, refere-se a vivências e sentidos.

Compreender o ser caracteriza a existência humana, pois ser-aí já é ser-com. Em meu estudo, o alcance da estrutura do fenômeno foi possível pela análise compreensiva e interpretativa dos depoimentos de quem, "ex-sistindo", vivencia a experiência: a mulher submetida a exame ginecológico para a prevenção do câncer cérvico-uterino.

\section{Aproximação ao ser-mulher}

Encontrando-me afastada da clientela específica desta pesquisa, iniciei, a partir da primeira quinzena de maio de 1994, um retorno ao mundo-vida de um ambulatório de clínica ginecológica. Com essa proposta, busquei, também, desenvolver e assumir a postura fenomenológica pertinente a todos os passos de uma pesquisa de tal natureza.

Para o acesso às mulheres, optei pelo Centro de Ginecologia Luiza Gomes de Lemos (CGLGL), instituição pública subordinada ao Ministério da Saúde e absorvida, há cerca de três anos, pelo Instituto Nacional do Câncer, órgão de pesquisa, que estabelece políticas de combate ao câncer através do Programa de Oncologia (PRO-ONCO).

Localizado na zona norte da cidade do Rio de Janeiro, no bairro de Vila Izabel, essa unidade de tratamento e de pesquisa é denominada INCa III. Não é de porte emergencial e não realiza acompanhamento prénatal, exames laboratoriais para o diagnóstico de gravidez, nem outros exames solicitados por médicos que não os da unidade, nem tratamento de problemas de ginecologia geral, sendo todos esses casos encaminhados para outras instituições.
O CGLGL tem como finalidades a prevenção, o diagnóstico precoce e o tratamento de câncer de mama, câncer ginecológico ou problemas correlatos, incluindose nesse grupo as doenças que, não sendo diagnosticadas e, conseqüentemente, não tratadas adequadamente, cancerizam-se.

Procurei, inicialmente, a chefia da Divisão de Enfermagem, no sentido de relatar minha proposta de estudo e de pedir-lhe autorização para a utilização do CGLGL como campo para a realização das entrevistas. Nessa ocasião, descrevi, verbalmente, alguns aspectos importantes do estudo como: objeto, objetivo, questão norteadora e coleta dos depoimentos. Informei-lhe que, sendo este o primeiro contacto, consistia numa iniciativa de minha parte. Caso fosse aceita, oficializaria minha presença na instituição através de documento a ser encaminhado pela Coordenação Geral de Pós-Graduação e Pesquisa da Escola de Enfermagem Anna Nery/UFRJ. Mediante o parecer favorável e a informação de não haver a necessidade de encaminhamento de documentação, ofereceu-me total apoio.

Fui encaminhada à enfermeira responsável pelo ambulatório a quem detalhei os aspectos anteriormente citados e, juntas, analisamos o momento e o local apropriados para abordar as depoentes, sem que viesse a comprometer o fluxo de atendimento. Fui informada da rotina e do atual Programa de Atendimento de Enfermagem na Prevenção Ginecológica da instituição, segundo o qual, a partir de março de 1994, ficara determinado como critério para a execução de atendimento por enfermeiras, a realização do exame preventivo, exclusivo a clientes em acompanhamento médico pós-mastectomia e/ou segmentectomia, que desejassem fazer esse controle durante os cinco anos subseqüentes à cirurgia.

Com o objetivo de aproximação à esse cenário, bem como da equipe e da clientela, antes da coleta dos depoimentos compareci à instituição por outras quatro vezes. Conheci as dependências do ambulatório, acompanhei consultas de enfermagem a clientes mastectomizadas que realizavam seus preventivos ginecológicos como medida de controle e assisti a palestras que foram realizadas sob a responsabilidade do serviço de enfermagem e do serviço social.

A rotina de atendimento à clientela que busca essa instituição inclui uma palestra diária oferecida às 07:00 h, nos dias úteis, com uma duração média de 40 minutos. Em um auditório fornece informações através da exposição oral e da projeção simultânea de slides, não só da atual filosofia do INCa III e do processo de triagem, bem como do conceito de câncer e das medidas preventivas, de diagnóstico precoce e de tratamento do câncer cérvico-uterino e de mama. Nesse encontro, são abordados o conceito de câncer, os sinais de alerta para a 
doença, a importância e a técnica do auto-exame de mama, a atual periodicidade do preventivo ginecológico preconizada pelo Ministério da Saúde, sendo enfocados, superficialmente, os tabus relativos à avaliação ginecológica. Como barreiras à realização do exame são ressaltados: o constrangimento, a vergonha, o medo e a ansiedade, sendo afirmado que o que mata não é a doença e, sim, o preconceito e os tabus. A clientela é também informada de que é necessário fazer exame preventivo independente de sintomatologia e que a idade preconizada para o início dessa prática é 20 (vinte) anos para virgens $\mathrm{e}$, inferior a essa, para aquelas que já iniciaram a atividade sexual. A necessidade de consultas ginecológicas, independente da realização do exame preventivo, é reforçada. Embora seja permitida aos acompanhantes a participação na palestra, é vedada sua entrada nos consultórios, salvo nos casos de clientes com problemas físicos e/ou mentais severos ou em virtude de detecção posterior dessa necessidade pelo médico responsável pelo atendimento. É garantida a permanência de uma auxiliar de enfermagem durante todo o atendimento.

A consulta envolve a realização de anamnese dirigida, o exame físico, a inspeção especular com a coleta de material colpocitológico, o toque vaginal ou retal e o registro, em formulário próprio, das características anátomo-fisiológicas, dos achados significativos, da hipótese diagnóstica e da orientação terapêutica.

Nesses momentos entendidos por ambientação ou incursão no mundo-vida de uma instituição, abordei mulheres no pátio externo, logo após a realização da palestra. Para cada mulher, apresentava-me como enfermeira e docente da Escola de Enfermagem da Universidade Federal do Rio de Janeiro, interessada em compreender sua vivência em exame ginecológico para a prevenção do câncer cérvico-uterino e descrevia-lhe, em síntese, a proposta de investigação científica.

Com a preocupação de possibilitar a adequação das entrevistadas à proposta do estudo questionava-lhe, antes de proceder a coleta do seu depoimento, se a busca por essa instituição fora espontânea e se a vivência em exame ginecológico preventivo era relacionada não à finalidade curativa, mas, sim, à de diagnóstico precoce do câncer cérvico-uterino. Mediante uma resposta afirmativa, indagava a cada mulher se gostaria de participar da pesquisa através de uma entrevista, sem roteiro e limite de tempo, na qual ela poderia falar livremente o que desejasse sobre essa vivência. Garantindo-lhe sobre a manutenção do sigilo e do anonimato, indagava-lhe o nome, a idade atual, a idade ao fazer o primeiro exame ginecológico para a prevenção do câncer de colo de útero e a periodicidade com que o realizava. Discutia com elas a possibilidade de utilizar o gravador e, havendo a sua anuência, prosseguia o encontro, fazendo a gravação do depoimento. Solicitava, então, a sua fala sobre essa vivência, sobre o significado do exame aos seus olhos e o modo como se sentia em relação à dinâmica do procedimento.

Nesses momentos que precederam à coleta dos depoimentos, pude esclarecer e ajustar alguns aspectos importantes para a realização das entrevistas, tais como: seleção da questão norteadora, local e horário para a coleta dos depoimentos e utilização do gravador.

Esses momentos possibilitaram-me, de forma gradativa e com as dificuldades próprias a uma principiante nesta modalidade de abordagem desafiadora, ir reduzindo a postura pré-julgadora e despojando-me de pressupostos. Ao assumir e manter a postura fenomenológica pude desenvolver a relação empática fundamental à coleta de depoimentos mediante a entrevista fenomenológica e decisiva ao propósito de aproximação e encontro com o outro, como possibilidade de compreensão.

SOUZA $^{9}$ e PAZ $^{7}$ também perceberam a relevância desses momentos para o pesquisador que tem na abordagem fenomenológica a experiência nova e desafiadora de estabelecer com o outro uma relação de possibilidade de compreensão. Segundo CARVALHO ${ }^{3}$, é o exercício que nos prepara para que, através da entrevista fenomenológica, possamos captar a maneira do outro vivenciar o mundo.

Entrar em contato com a vivência da mulher, através de sua fala originária, possibilitou-me vê-la como pessoa no seu cotidiano, como ela se mostra com o seu modo próprio de ser, em seu sendo. Assim, a partir do que emergiu desses encontros prévios pude decidir-me por: entrevistar as mulheres no pátio interno da instituição, logo após a palestra, enquanto aguardavam o encaminhamento à sala de consulta e utilizar o gravador após a aquiescência das mesmas. Pude também definir a questão norteadora.

Sentadas em cadeiras dispostas num longo corredor, preservada a sua privacidade, respondiam individualmente à solicitação: "Descreva para mim: o que significa para você fazer o exame ginecológico para a prevenção do câncer de colo de útero."

Os dias destinados para a ida à instituição tiveram relação direta com a minha disponibilidade de serviço. As atividades de pesquisa, enquanto entrevistadora, ocorreram em dois períodos diferenciados: o da ambientação - de 13 de abril a 24 de maio de 1994, quando tive a oportunidade de entrevistar 10 (dez) mulheres; e o segundo grupo - de 01 de julho a 06 de setembro de 1994, com 18 (dezoito) depoentes.

As depoentes não apresentaram objeção ao uso do gravador, não sendo também percebida qualquer inibição. De um modo geral, apresentaram-se ávidas por falar e poder, assim, compartilhar o mundo próprio a cada uma, através do relato de suas experiências vividas em 
exame ginecológico para a prevenção do câncer cérvicouterino, possibilitando o manifestar-se, o mostrar-se próprio do ser de cada mulher.

Após o término de cada entrevista, retrocedia a fita correspondente ao último depoimento e comunicavalhe que, juntas, ouviríamos a gravação como oportunidade de verificar o que expressara e, caso desejasse, de complementar ou modificar o já dito. Não houve nenhum caso de alteração, mas ouvir a gravação foi para muitas motivo de surpresa, satisfação e/ou de constrangimento, tendo algumas me confidenciado que nunca tinham ouvido o registro de suas próprias vozes.

Após entrevistar cerca de duas depoentes ao dia, encaminhava-me para o pátio interno e procurava mergulhar, mesmo que de forma incipiente, no movimento próprio de cada uma, reportando-me, mentalmente, a cada encontro. Voltava a minha atenção para o mundo próprio da linguagem, da totalidade das palavras, dos gestos, do silêncio, do tom de voz e da expressão facial, como o primeiro ensaio de captação do sentido, a partir do modo singular e único de cada humano intencionar o mundo.

A coleta dos depoimentos, através da entrevista fenomenológica, permitiu-me o encontro com as mulheres, enquanto existentes, e que, segundo HEIDEGGER ${ }^{5}$ “... de acordo com seu modo de ser de presença, são e estão no mundo em que vêm ao encontro segundo o modo ser ser-no-mundo."

Assim, cada presença enquanto ser-aí-com-ooutro permite o encontro de muitos em seu mundo.

\section{ANÁLISE COMPREENSIVA}

Da obtenção dos depoimentos passei à transcrição e à leitura preliminar, reportando-me, novamente, ao momento do encontro, no intuito de tornar cada relato familiar. Foi um movimento de ler, sem ajuizar ou ter a preocupação interpretativa do ali expresso. Após desenvolver esse procedimento para cada depoimento em separado, fiz e refiz várias leituras seqüenciais da totalidade do coletado na tentativa do alcance do que as mulheres expressavam em seus relatos, a partir do seu "ex-sistir", dirigidas pela questão norteadora e mediadas pela empatia.

Com a leitura atentiva, iniciei a apreensão dos significados atribuídos pelas mulheres ao exame ginecológico de caráter preventivo. As mulheres mostraram-se através dos seus sentimentos, pensamentos, ações e percepções contidos em suas descrições.

A partir da leitura dos significados atribuídos, passei a estruturar as unidades de significação, que caracterizam a facticidade. Tal construção é conduzida pelo sentido e as unidades de significação expressam a minha compreensão da visão das depoentes. Esse movimento já denuncia a captação do sentido, que está presente no discurso, de modo velado. As unidades de significação foram assim construídas:

- busca de assistência de saúde representada pela figura do médico, que garante a mulher apoio e segurança; - expectativa de apresentar uma doença, negada muitas vezes, através de eufemismos e que a espreita como indicativo de morte; - vivência ambígua de expectativa, medo, dor, vergonha, aceitação e tranqüilidade; - vivência que referencia a experiência de outras mulheres; vivência obrigatória e inerente à mulher e que demonstra responsabilidade para com sua saúde; - experiência vivenciada com o suporte de uma crença em um Ser Supremo; - vivência permeada pela sexualidade com o resgate das lembranças da intimidade sexual, da gravidez e do parto; e - vivência reveladora de relações profissionais que indicam poder mediante atitudes ambivalentes de atenção, de carinho e de rispidez.

Com o interesse na busca do sentido, o pensar heideggeriano foi o referencial para interpretar compreensivamente os modos de ser que fundam a experiência concreta do vivido das mulheres, quando da realização do exame ginecológico para a prevenção do câncer cérvico-uterino. A análise existencial apresentada em Ser e Tempo foi o suporte para o desvelamento do fenômeno pesquisado.

Refletindo sobre o objeto de estudo - o sentido que funda o "ex-sistir" da mulher no que se concerne à realização do exame ginecológico, para a prevenção do câncer cérvico-uterino - a etapa da hermenêutica consistiu no movimento de buscar o avesso desse "ex-sistir", tendo como referência a análise do fenômeno da "ex-sistência" cotidiana desenvolvida por HEIDEGGER ${ }^{5}$.

Partindo das unidades de significação de onde emergiram os aspectos ônticos, isto é, tudo o que é percebido de forma imediata, encaminhei o meu pensar para a ultrapassagem do verbalizado, na tentativa de desvelar o sentido velado nos depoimentos e, assim, apreender os aspectos ontológicos da presença - o que possibilita as várias maneiras de algo se tornar manifesto.

Nesta etapa interpretativa, procedi a uma deconstrução das descrições a partir da compreensão de que, nestas, a mulher, como presença, escapa aos conceitos que dela se faz e iniciei um movimento de construção de busca do sentido que funda seu dizer. Nesse sentido, o movimento de de-construir, proposto por Heidegger, não possui o caráter negativo de negar ou de anular o saber factual. É um desmontar a facticidade e um mostrar o que obscurece o sentido, construindo a instância do fenômeno.

Assim, a singularidade do comportamento da mulher foi interpretata compreensivamente à luz dos modos de ser do existir cotidiano, não sendo apontadas e 
valorizadas as situações existenciais esporádicas, mas, sim, as essenciais; estas que denunciam como a presença é antes de tudo e na maioria das vezes. Nesse entendimento, emergiram alguns conceitos expressos em Ser e Tempo e que foram desenvolvidos na construção do sentido a seguir apresentado:

- vivenciar o exame ginecológico é para o ser-mulher pautar seu comportamento pela inautenticidade; é desvelar-se descompromissada com o ser mesmo da atividade assistencial de caráter preventivo;

- a situação do exame ginecológico propicia o desvelamento do existir inautêntico como um modo de ser da mulher e do profissional, enquanto presenças coexistentes e anuncia o processo de desumanização como possibilidade;

- o temor como disposição imprópria é um modo de ser da mulher que na abertura, no pré da presença, tem no exame a vivência da ameaça;

- a situação do exame ginecológico remete o ser-mulher à sua condição originária. Enquanto presença temerosa, foge ao chamamento da possibilidade de não ser-maisaí;

- ser-mulher na realização do exame ginecológico para a prevenção do câncer cérvico-uterino é compreender a autenticidade como um modo de ser; é desvelar-se como cura.

\section{CONSIDERANDO \\ A \\ ABORDAGEM METODOLÓGICA}

A Fenomenologia, cujo referencial foi eleito para abordagem metodológica no desenvolvimento da referida investigação levou-me a repensar o conceito de conhecimento e a olhar o outro, acolhendo-o, sem julgamentos, em suas percepções, sentimentos e modos de ser. Assim, aproximando-me da proposta fenomenológica, voltei meu olhar para compreender a situação assistencial a partir daquela que, como sentido, tem, no exame, a vivência de vergonha, de ansiedade e de medo.

O olhar comprensivo que essa abordagem possibilitou não se refere a um mero conhecimento objetivo através da capacidade de sentir o que o outro experiencia. Diz respeito ao poder de captar as possibilidades que cada um é, no contexto do mundo em que cada presença existe e compartilha experiências.

\section{PHENOMENOLOGY AS A METHODOLOGIC REFERENCE: SHARING THE EXPERIENCE OF WOMEN WHO SEARCH FOR THE PREVENTION OF CERVICAL CANCER}

The article has the purpose to bring out the experience of having phenomenology as a methodological reference and Martin Heidegger's philosophical thinking expressed in the book entitled "Being and Time", used by nursing in order to understand women who search for the prevention of cervical cancer as well as to analyse the health programs offered to women.

KEY WORDS: nursing, women's health programs, phenomenology, methodology of phenomenology, investigation

\section{LA FENOMENOLOGÍA COMO ABORDAJE METODOLÓGICO: COMPARTIENDO LA EXPERIENCIA DE MUJERES QUE BUSCAN LA PREVENCIÓN DE CÁNCER CERVICO UTERINO}

El articulo presenta la experiencia de la utilización por enfermería de la fenomenología como abordage metodológico y el pensamiento filosófico de Martin Heidegger expresado en el libro Ser y Tiempo, a fin de comprender la mujeres que busca la prevención del cáncer cérvico-uterino y además possibilita reflexionar sobre la asistencia de salud a la mujer.

TÉRMINOS CLAVES: enfermería, salud a la mujer, fenomenología, metodología de investigación fenomenológica

\section{REFERÊNCIAS BIBLIOGRÁFICAS}

01. BOEMER, M.R. A fenomenologia na pesquisa em enfermagem. In: SEMINÁRIO NACIONAL DE PESQUISA EM ENFERMAGEM. 4., São Paulo. 2 a 5 de setembro 1985. Anais. São Paulo: Associação Brasileira de Enfermagem, 1985. p.90-94.
02. A condução de estudos segundo a metodologia de investigação fenomenológica, Rev.Latino-am.Enfermagem, Ribeirão Preto, v. 2, n.1, p.83-94, jan.1994.

03. CARVALHO, A.de S. Metodologia da entrevista: uma abordagem fenomenológica. 2. ed. Rio de Janeiro: Agir, 1991. 93p. 
04. DONZELLI, T.A. Método fenomenológico e ciências humanas. In: Leila Bugalho (org.) Teorização do serviço social. Rio de Janeiro: Agir, 1988. p. 44-49.

05. HEIDEGGER, M. Ser e tempo. 3, ed. Trad. Márcia de Sá Cavalcante. Petrópolis: Vozes, 1993. 325 p. (Coleção Pensamento Humano). (Parte 1)

06. LOPES, R.L.M. O avesso da prevenção do câncer cérvico-uterino: o ex-sistir feminino sob a ótica da enfermagem. Rio de Janeiro, 1996. p.1-5. Tese (Doutorado) - Escola de Enfermagem Anna Nery, Universidade Federal do Rio de Janeiro.
07. PAZ, E.P.A. O significado do ser-mãe cuidando da saúde do filho lactente. Rio de Janeiro,1994. p. 27-28. Tese (Mestrado) - Escola de Enfermagem Anna Nery, Universidade Federal do Rio de Janeiro.

08. REZENDE, A.M.de. Concepção fenomenológica da educação. São Paulo: Cortez: Autores Associados, 1990. 96 p. (Coleção Polêmicas do nosso tempo, v. 38).

09. SOUZA, I.E.de O. O des-velar do ser-gestante diante da possibilidade de amamentação. Rio de Janeiro, 1993. p. 27-28. Tese (Doutorado)Escola de Enfermagem Anna Nery, Universidade Federal do Rio de Janeiro. 